\title{
A follow-up study of coronary heart disease in viscose rayon workers exposed to carbon disulphide
}

\author{
M. TOLONEN, S. HERNBERG, M. NURMINEN, and K. TIITOLA \\ Institute of Occupational Health, Helsinki, and Säteri Co, Valkeakoski, Finland
}

Tolonen, M., Hernberg, S., Nurminen, M., and Tiitola, K. (1975). British Journal of Industrial Medicine, 32, 1-10. A follow-up study of coronary heart disease in viscose rayon workers exposed to carbon disulphide. In 1967 two cohorts of 343 men each were formed and matched with respect to age, district of birth, and similarity of work. One cohort comprised viscose rayon workers with at least five years' exposure to carbon disulphide during any period between 1942 and 1967, and the other cohort consisted of workers from a paper-mill with no such exposure. The concentrations of carbon disulphide and hydrogen sulphide in the workroom air had been measured regularly since 1950 , and about 4000 measurements were available. In all probability the concentrations had been very high in the 1940s, between 20 and $40 \mathrm{ppm}$ in the 1950s, and about 10 to $30 \mathrm{ppm}$ from 1960 onwards. On examination in 1967 it was confirmed that all of the relevant coronary risk factors had been kept under control. The only exception to this was blood pressure which was slightly higher among the exposed workers, a finding that was interpreted as a result of exposure rather than an independent risk factor. A five-year follow-up showed that 14 men had died from coronary heart disease (CHD) in the exposed group, against three in the control group ( $P<0.007)$. Other causes of death were evenly distributed. In addition, 11 nonfatal first infarctions had occurred in the exposed group as compared with four in the control group. On re-examination in 1972 , nearly $25 \%$ of the exposed men, against $13 \%$ of the controls, had a history of angina (typical, probable, and possible) as measured by the World Health Organization questionnaire $(\mathrm{P}<0.0002)$. The prevalence proportions of typical angina were $12 \%$ and $5 \%$ respectively $(\mathrm{P}<0.001)$. As opposed to this, only slight differences were apparent for coronary ECGs. The higher degrees of prevalence in the exposed group may well have been attributable to chance. As in 1967/68, the mean systolic and diastolic blood pressures were slightly higher in the exposed group $(P<0.001$ and $\mathbf{P}<0.01$, respectively). The relative risk was 4.8 for fatal attacks, 3.7 for all infarctions, $2 \cdot 8$ for nonfatal infarctions, $2 \cdot 2$ for angina, and 1.4 for ECG findings indicative of CHD. This implies that with increasing severity and specificity of the manifestations the causal role of $\mathrm{CS}_{2}$ in developing CHD becomes more evident. Further, it is inferred that exposure to $\mathrm{CS}_{2}$ seems to worsen the prognosis of $\mathrm{CHD}$ in addition to increasing its incidence. Although the exposure data in this study may not be representative of the personal exposure of the workers, the conclusion is drawn that a great deal of justification exists for lowering the threshold limit value of $20 \mathrm{ppm}$ recommended by the American Conference of Governmental Industrial Hygienists. 
It has become evident from recent epidemiological studies that combined occupational exposure to carbon disulphide $\left(\mathrm{CS}_{2}\right)$ and hydrogen sulphide $\left(\mathrm{H}_{2} \mathrm{~S}\right)$ increases the incidence of cardiovascular mortality, $\mathrm{CS}_{\mathbf{2}}$ being the most likely causative agent (Tiller, Schilling, and Morris, 1968; Mowé, 1971; Hernberg, Nurminen, and Tolonen, 1973). This is explicable either by the assumption that the pathophysiological processes responsible for the development of coronary heart disease (CHD) are accelerated, or by postulation of a more severe prognosis of the disease at a given severity of atherosclerotic changes in the coronary arteries. According to the former hypothesis the incidence and prevalence of all stages of the disease should be higher, whereas the latter implies in particular an increase in the incidence of severe manifestation such as death.

The well-known nonspecificity of the milder manifestations of CHD, mainly taking the form of electrocardiographic (ECG) abnormalities and a history of angina, creates methodological difficulties in exact estimation of the prevalence of nonfatal CHD. In comparative studies this weakness can to some extent be overcome only by careful standardization of the methods applied and by ensuring strict comparability of the populations under study; nevertheless the prevalence estimates so derived are far less specific than are recordings of clinical infarctions or coronary deaths. With this in mind it is not remarkable that no definite evidence can be adduced in favour of one or the other of the hypotheses put forward above from the few controlled morbidity studies that are available. Admittedly these studies included slightly increased prevalence of coronary ECG findings (Goto and Hotta, 1967; Hernberg, Partanen, Nordman, and Sumari, 1970; Cirla, Villa, and Tomasini, 1972) but as grading of the occurrence of manifestations of CHD of varying severity would require observations of all of them from the same populations, no such conclusions can be drawn from existing data.

An opportunity has presented itself to follow and re-examine a group of viscose rayon workers selected in 1967 on the basis of at least five years' exposure to $\mathrm{CS}_{2}$ during any period between 1942 and 1967. At the first examination in 1967/68 an investigation was made of the degrees of prevalence of different manifestations of CHD, which were compared with corresponding data in respect of a carefully selected control group (Hernberg et al., 1970). During the follow-up from 1967 to 1972 records were made of the incidence of fatal and nonfatal coronary infarctions in both groups, and in 1972 the frequency of CHD was re-studied by a clinical examination. The mortality data have already been reported (Hernberg et al., 1973), and thus this paper centres upon nonfatal CHD. Another aim has been of analysing the predictive value of the coronary risk factors recorded in 1967 to the subsequent development of clinical CHD.

\section{Material and design}

The original set-up of the study has been described in detail in earlier publications (Hernberg et al., 1970; Hernberg et al., 1973). To summarize, the exposed cohort comprised 343 men with at least five years' exposure to $\mathrm{CS}_{2}$ during any period between 1942 and 1967. All of the men were or had been employed by the same viscose rayon plant. They were all individually matched with workers from a nearby paper-mill. The matching factors were age, district of birth, and type of work. The most relevant coronary risk factors (including smoking history, habitual physical activity, blood lipids, and relative body weight), with the exception of blood pressure, were equally distributed in both groups at the initial examination. However, the slightly higher blood pressure found in the $\mathrm{CS}_{2}$ group was interpreted as being an effect of exposure rather than an independent risk factor. A recheck of the same factors was made in 1972; no deviations of practical significance had developed during the followup except for blood cholesterol, which was then found to be slightly higher in the exposed group. Since an $a$ posteriori evaluation of the matching scheme indicated that the matching was irrelevant, it was decided that the pairs would be broken up and the data treated as constituting two independent series (Hernberg et al., 1973).

During the follow-up from 1 July 1967 to 30 June 1972, 21 exposed and nine nonexposed men had died. Thus, of the original $343+343$ men, $322+334$ were still alive. Of these, two control subjects could not be reexamined by reason of severe illness. The groups examined in 1972 thus comprised 322 exposed and 332 nonexposed subjects. The exposure situation of the exposed cohort in June 1972 is illustrated in Table 1.

\section{The toxic environment}

The plant comprises four factories-one for the production of rayon staple fibres, one for rayon filament, one for viscose films, and one for the synthesis of $\mathrm{CS}_{2}$. The average levels of $\mathrm{CS}_{2}$ and $\mathrm{H}_{2} \mathrm{~S}$ in the workroom air of each factory are illustrated in Figures 1 to 4. As major fluctuations in the $\mathrm{CS}_{2}$ concentrations had occurred throughout the years and as most of the subjects had held different jobs during the course of their employment, extreme difficulty was experienced in classification of the

\section{TABLE 1}

Present Exposure Status of the Exposed COHORT IN JUNE 1972

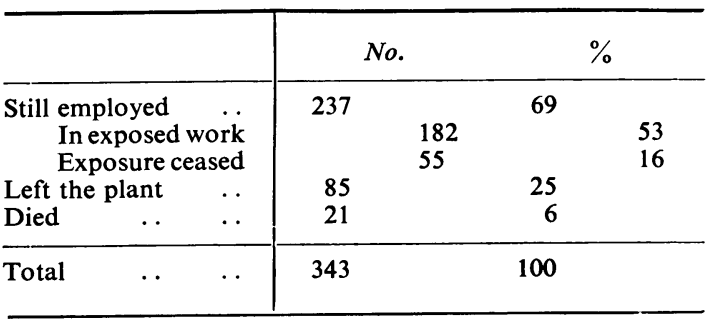




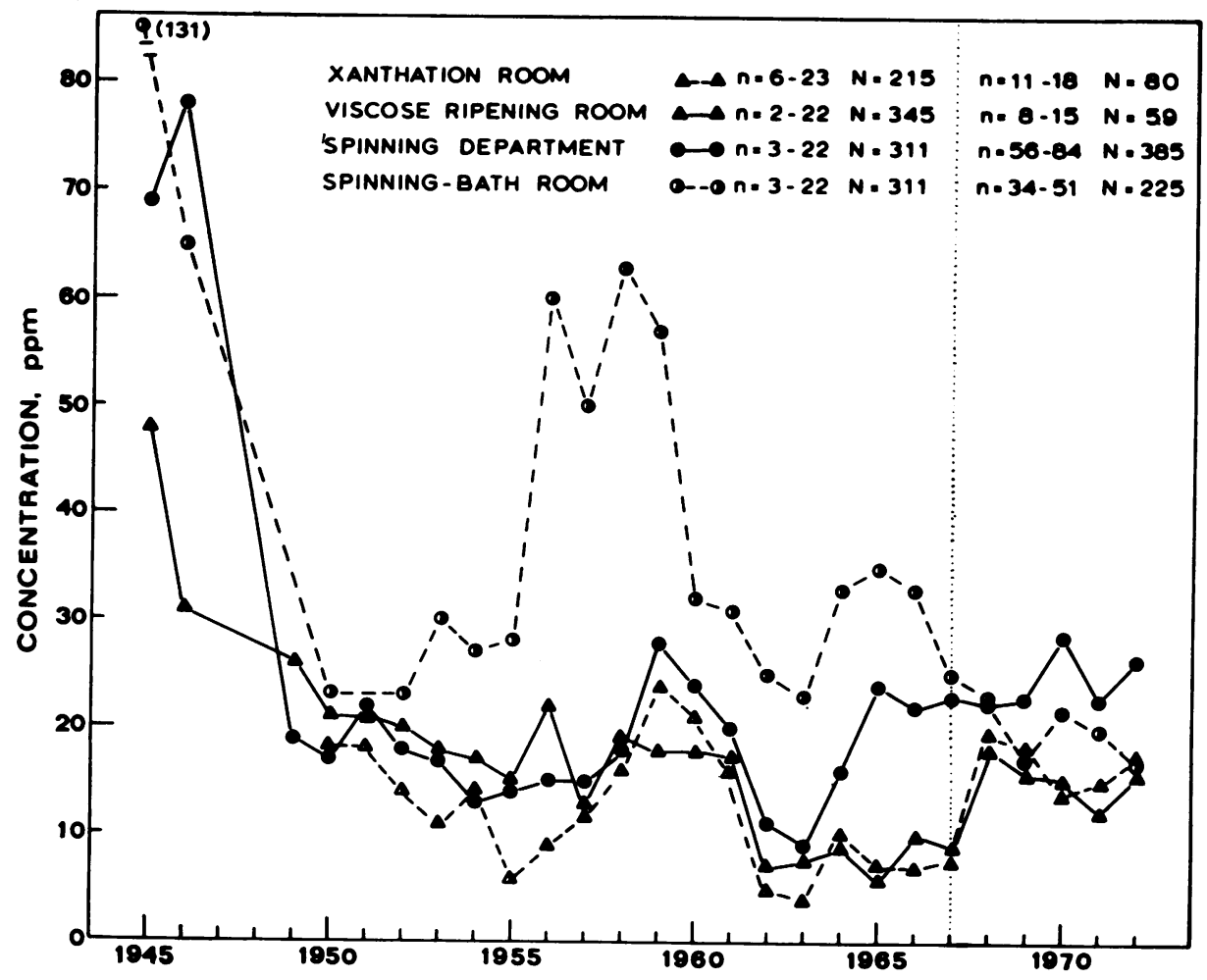

FIG. 1. Concentration of $\mathrm{CS}_{2}+\mathrm{H}_{2} \mathrm{~S}$ (arithmetic means) in the air of the rayon staple factory; $\mathrm{n}=$ number of samples per year; $\mathrm{N}=$ total number of samples 1945-67 and 1967-72.

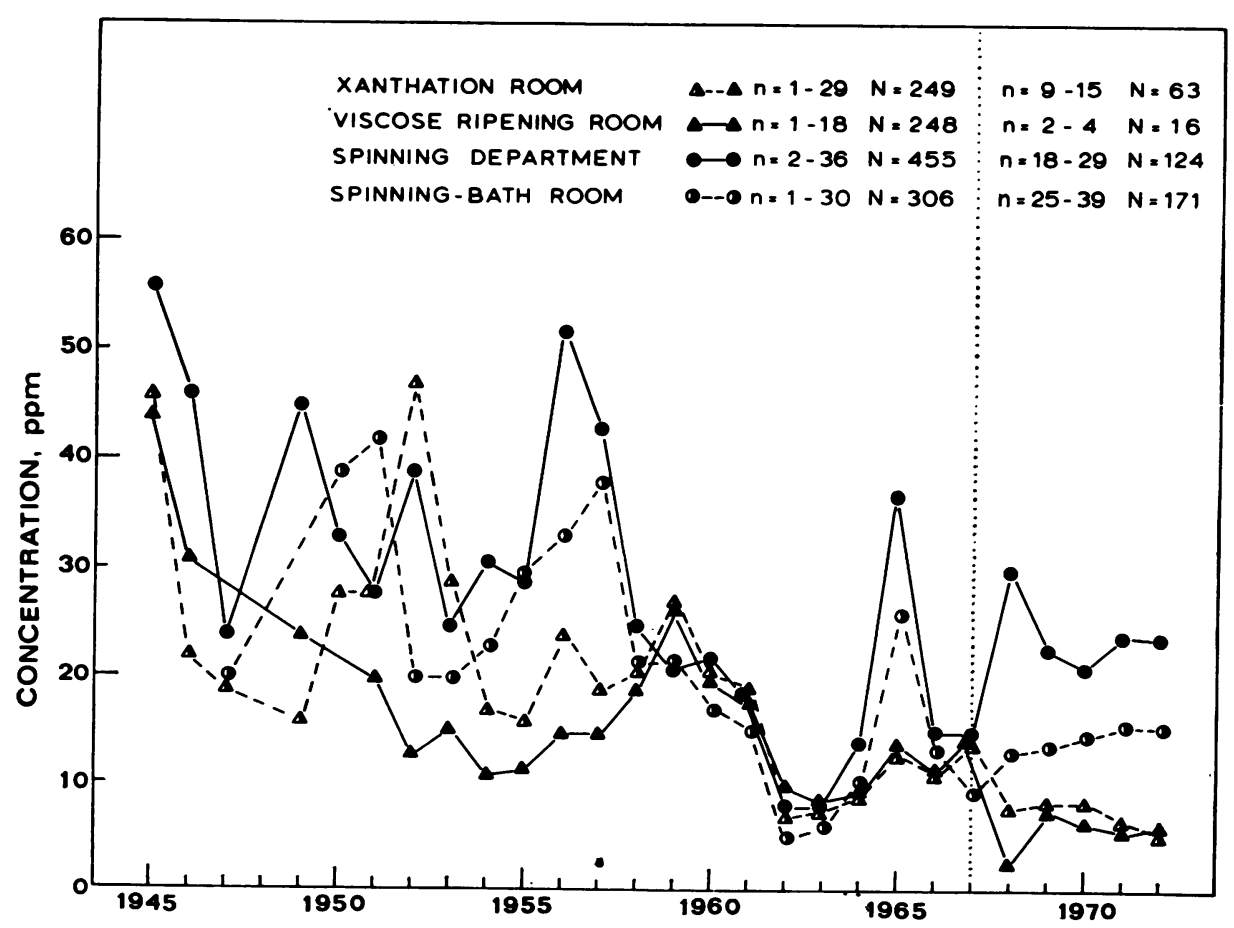

FIG. 2. Concentration of $\mathrm{CS}_{2}+\mathrm{H}_{2} \mathrm{~S}$ (arithmetic means) in the air of the rayon filament factory; $\mathbf{n}=$ number of samples per year; $\mathbf{N}=$ total number of samples 1945-67 and 1967-72. 


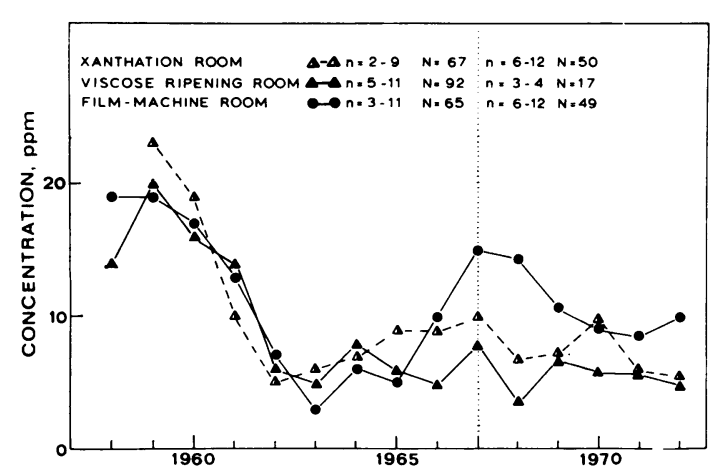

FIG. 3. Concentration of $\mathrm{CS}_{2}+\mathrm{H}_{2} \mathrm{~S}$ in the air of the viscose film factory; $\mathrm{n}=$ numbers of samples per year; $\mathrm{N}=$ total numbers of samples 1958-67 and 1967-72.

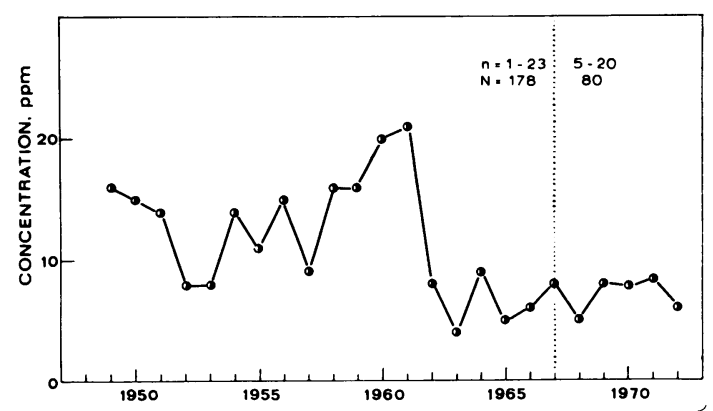

FIG. 4. Concentration of $\mathrm{CS}_{2}+\mathrm{H}_{2} \mathrm{~S}$ in the air of the $\mathrm{CS}_{2}$ factory; $\mathrm{n}=$ number of samples per year; $\mathrm{N}=$ total number of samples between 1948-67 and 1967-72.

workers according to the intensity of exposure. For this reason an exposure index constructed as a function of time and $\mathrm{CS}_{2}$ concentration during that period was calculated for each exposed worker (Hernberg et al., 1970). However, not even this index can be expected to provide an exact description of the exposure, since for short periods most workers had repeatedly been exposed to much higher concentrations during disturbances in the ventilation system while having to work with their heads inside the machine covering, and so on. Such conditions occur quite frequently, but as no data were available on either their frequency or the $\mathrm{CS}_{2}$ levels reached, their effect on the exposure index could not be estimated.

\section{Methods}

To ensure comparability, all of the methods applied corresponded exactly to those used in 1967/68. As a detailed description has already been published (Hernberg et al., 1970; Hernberg, Nordman, Christiansen, and Virkola, 1971), no more than a short recapitulation is provided here.

The coronary history was elicited by means of a questionnaire (World Health Organization, 1963). Inquiries concerned both former infarctions and present angina.
The blood pressure was measured by one of the authors (M.T.), with the same mercury column equipped with a wrap-around cuff $(14 \times 65 \mathrm{~cm})$, and a stethoscope. After the subject had rested for at least 15 minutes, the blood pressure values were recorded from the right arm at room temperature with the subject in the sitting position as described earlier (Hernberg et al., 1970).

ECG recordings were made by the same device and with the same standardized criteria as before (Hernberg et al., 1970). The subjects had the same four-minute non-gradual submaximal exercise on a bicycle ergometer as five years previously, even when they had reached an older age group. In only a few cases did medical or physiological contraindications exist. The recordings were coded by the Minnesota code (Blackburn et al., 1960) by two technicians independently, and any differing codes were re-analysed jointly. Tests were made of the inter-observer error in coding now and in 1968 by the employment of films made in $1967 / 68$. The results did not indicate any systematic differences between the coders.

The heart volumes were calculated from anteroposterior and lateral radiographs of the chest by application of the formula given previously (Hernberg et al., 1970).

Statistical manipulation of the data on CHD from the follow-up was based upon calculation of incidence and prevalence rates for the two cohorts. Comparisons of the rates were effected both cross-sectionally between the cohorts in 1972 and also longitudinally within the cohorts from 1967 to 1972 . Significance-testing of the differences was performed by means of an approximately standard normal deviate (denoted by the letter $\mathrm{z}$ ) and two-tailed probability levels associated with the test values obtained. The methods of estimation of the relative risks and their confidence limits were the same as those employed in a previous study (Hernberg et al., 1973). The evaluation of discrepancies in the distributions of coronary risk factors was effected either by Student's $t$ test for the mean values or by the Kolmogorov-Smirnov test for the cumulative frequencies (denoted by the letter D).

For the assessment of a possible dose-response effect within the exposed group subjects with fatal and nonfatal infarction as well as those with anamnestic angina ('cases') were given one pair each without any symptoms or signs of CHD ('controls') from the exposed group. The matching criterion was age ( \pm 2 years). This retrospective approach permits a check on the confounding effect of age in the study of the relation between CHD and exposure. The average exposure time and the average exposure index along with some coronary risk factors were then compared for the cases and the controls. Similarly, cases of infarction and angina from the whole population (exposed + nonexposed) were given controls without $\mathrm{CHD}$, and comparisons were made of the distributions of some coronary risk factors as measured in $1967 / 68$.

\section{Results}

\section{Coronary mortality}

The mortality figures for a follow-up period of 5.5 years have been presented in a previous publication (Hernberg et al., 1973). During that period 
16 coronary deaths occurred in the exposed group as compared with three among the controls. In the context of the present paper, the follow-up period had to be cut off at $5 \cdot 0$ years as this corresponded to the time at which the clinical examination was made. During this period the fatal infarctions numbered 14 in the exposed and three in the control group.

\section{Nonfatal myocardial infarctions}

During 1967 to 197211 exposed and four nonexposed men had incurred and survived their first myocardial infarction. On addition of these figures to the numbers of fatal attacks the total incidence of clinical infarctions during the five-year period from 1967 to 1972 was 25 in the exposed group and seven in the comparison group (Table 2).

\section{Electrocardiographic findings}

Table 3 illustrates a comparison of the rates of prevalence of positive coronary Minnesota codes from ECGs obtained in 1967/68 and in 1972. The

\section{TABLE 2}

OBSERVED NUMBER AND INCIDENCE (\%) OF MYOCARDIAL INFARCTIONS

(FATAL AND NoNfatal) AMONG THE EXPOSED AND COMPARISON COHORTS DURING THE FIVE-YEAR FOLLOW-UP AND AN ESTIMATE OF THE Relative RisK With the Associated CONFIDENCE LiMIT

\begin{tabular}{c|cccc}
\hline Cohort & $\begin{array}{c}\text { Number } \\
\text { observed }\end{array}$ & $\begin{array}{c}\text { Incidence } \\
/ 5 \mathrm{yr} \%\end{array}$ & $\begin{array}{c}\text { Relative } \\
\text { risk }\end{array}$ & $\begin{array}{c}95 \% \\
C L^{2}\end{array}$ \\
\hline Exposed .. & 25 & 7.5 & 3.7 & $1.4-9.6$ \\
Nonexposed & 7 & $2 \cdot 1$ & & \\
\hline
\end{tabular}

'Significance of the difference in incidence rates:

$z=3.24, P=0.0012$.

$395 \%$ confidence limits of the relative risk slight differences between the cohorts might all have been attributable to chance ( $P$ values $>0.05)$. The total number of pathological findings was slightly higher in 1972 than in $1967 / 68$. The most likely explanation for this was to be found in the higher age of the subjects at the later examination.

\section{History of angina}

The questionnaire employed allowed a classification of reported chest pain into none, a typical possible, probable, and typical angina (Table 4). All of the categories of angina were more prevalent in the exposed cohort both in $1967 / 68$ and in 1972. The difference, which was greatest for probable angina in $1967 / 68(z=2.07, P=0.04)$, was greatest for typical angina in 1972, as compared with nonexposed subjects $(z=3.31, P<0.001)$.

The total number of those who had had any of the classified symptoms of angina in 1972 was nearly twice as high in the exposed group as in the control group $(z=3.84, P<0.00012)$. As compared with $1967 / 68$, a positive history of angina was slightly more prevalent in 1972 among the controls $(\mathrm{z}=0.81, \mathrm{P}=0.42)$ but was distinctly so in the exposed group $(z=2 \cdot 49, P=0.013)$. The additional five years of age may explain the result for the control group, but hardly more than part of the increase in the exposed cohort. Moreover, the various categories of angina did not remain constant during the follow-up, since many of those who gave a history of angina in 1967/68 were free from symptoms in 1972, and vice versa. For example, $22 \%$ of the exposed and $34 \%$ of the nonexposed who had in 1967/68 been classified as having typical angina were free from symptoms in 1972. This may reflect either the natural course of CHD with better and worse periods, the nonspecificity of the questionnaire method or both. Similar results have been obtained previously from the repeatability testing of angina questionnaires. Intervals as short as three to 10 months have resulted in more than $50 \%$ of the persons studied answering differently. Notwith-

TABLE 3

Prevalence (\%) of Selected ECG Findings according to the Minnesota Code

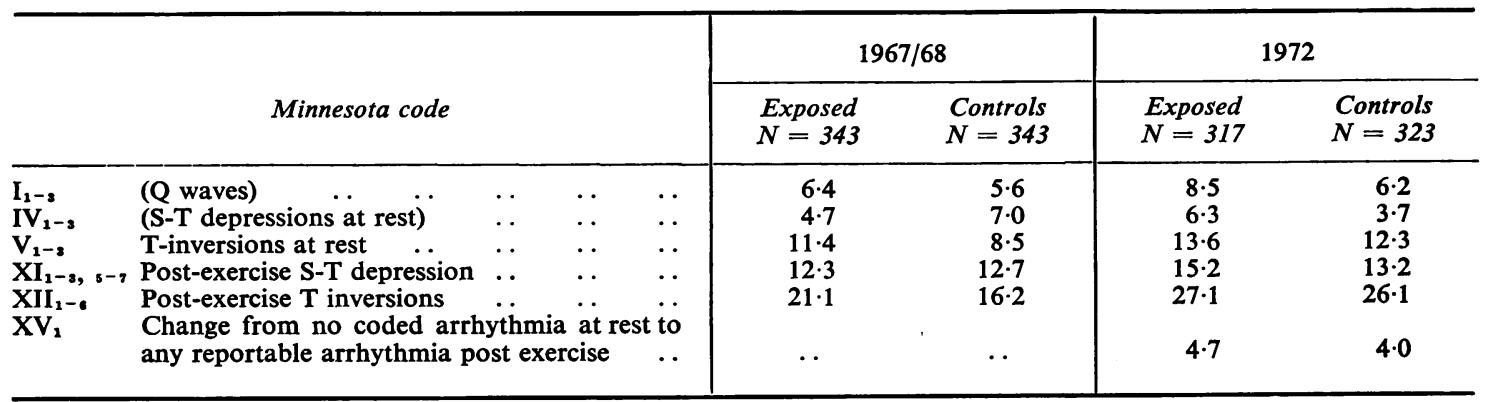


TABLE 4

Prevalence (\%) of Reported Chest Pain in Exposed and Comparison Cohorts in 1967/68 and 1972, Probability of Difference between the Rates being due to Chance, and an Estimate of the RELATIVE RisK

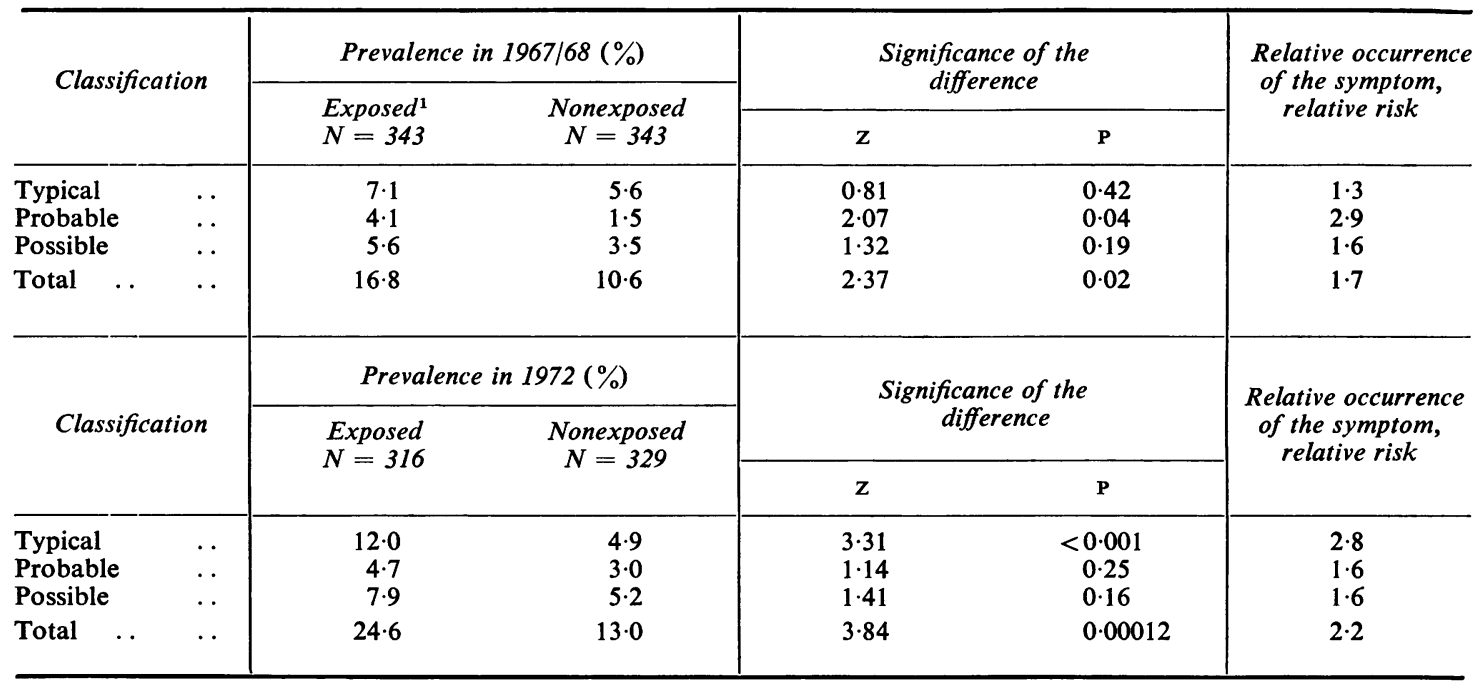

'In three cases, reported information was lacking.

standing this, the prevalence of rates of the different categories of angina tend to remain the same within a group (Rose, 1968; Zeiner-Henriksen, 1972). In a study with a longer time span such differences tend to become even more accentuated for natural reasons.

\section{Summary of manifestations of CHD}

Table 5 lists the relative risks and attributable risks for different manifestations of CHD in order of severity. It is observable that the risk ratio is highest for fatal infarctions and lowest for isolated ECG findings. This denotes that the more severe the outcome is, the more evident is the effect of carbon disulphide exposure. On the other hand the attributable risk is highest for angina, that is, in absolute figures more such cases occurred than there were

\section{TABLE 5}

Estimates of Relative Risk and Attributable RISK (\%) OF CHD ACCORDING TO SEVERITY of MANifESTATION

\begin{tabular}{|c|c|c|c|}
\hline Manifestation & & Relative risk & Attributable risk \\
\hline $\begin{array}{l}\text { Fatal infarction } \\
\text { All infarctions } \\
\text { Nonfatal infarction } \\
\text { Angina } \\
\text { 'Coronary' ECG }\end{array}$ & $\begin{array}{l}\cdots \\
\cdots \\
\cdots \\
\cdots \\
\cdots\end{array}$ & $\begin{array}{l}4 \cdot 8 \\
3 \cdot 7 \\
2 \cdot 8 \\
2 \cdot 2 \\
1 \cdot 4\end{array}$ & $\begin{array}{r}3 \cdot 2 \\
5 \cdot 4 \\
2 \cdot 2 \\
11 \cdot 6 \\
6 \cdot 1\end{array}$ \\
\hline
\end{tabular}

coronary deaths in the group exposed to carbon disulphide.

\section{Blood pressure}

In all age categories the average blood pressure was consistently higher in the exposed group. Figures 5 and 6 illustrate the cumulative frequency distribution of the systolic and diastolic blood pressures in both groups. The maximum differences observed between the cumulatives for the systolic $(D=17 \%)$ and diastolic blood pressure $(D=14 \%)$ exceeded the

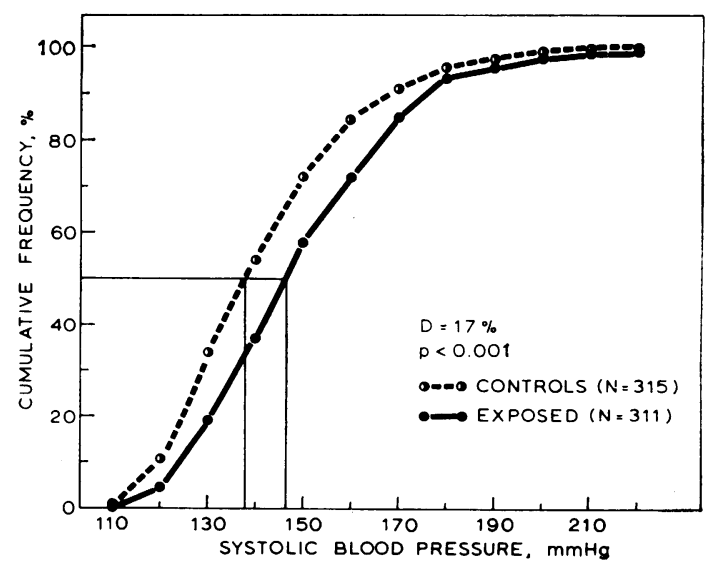

FIG. 5. Cumulative distribution of systolic blood pressure among the exposed and comparison groups. 


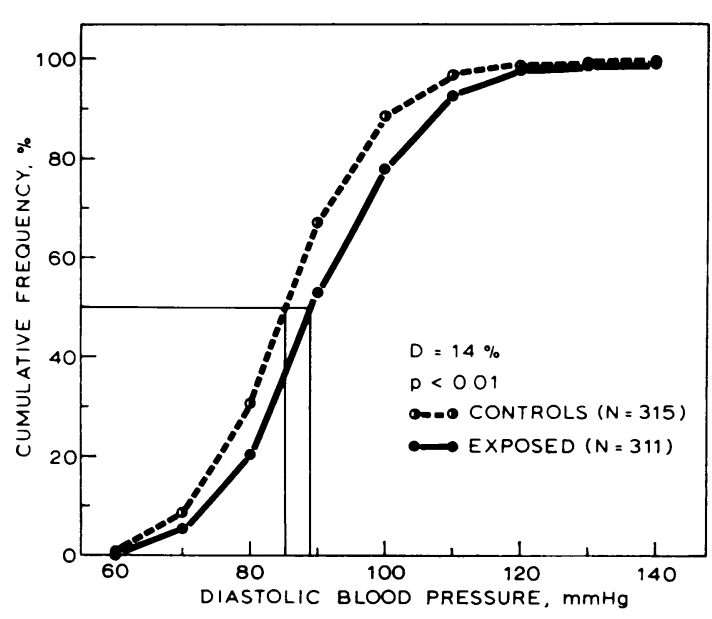

FIG. 6. Cumulative distribution of diastolic blood pressure among the exposed and comparison groups.

critical values at probability levels $P<0.001$ and $P<0.01$, respectively. The differences between medium values obtained from the figures were $8 \mathrm{mmHg}$ for the systolic and $3,5 \mathrm{mmHg}$ for the diastolic pressure. The results are in close correspondence with those obtained in 1967/68. Since differences of this kind might arise from systematic differences in vascular stress reactions brought about by the examination situation (for instance, for some reason or other the exposed men might have been more tense), the mean heart rates at rest were checked from the ECGs. The results were identical for both groups: 73 beats per minute (SD = 13). In view of this it seems unlikely that the higher blood pressures measured in the exposed group had been triggered by emotional stress.

\section{Heart volume}

Only slight differences were apparent between the relative heart volume of the exposed and nonexposed cohorts. The former group had a mean volume of $379 \mathrm{ml} / \mathrm{m}^{2}(\mathrm{SD}=100)$ while the latter had $376 \mathrm{ml} / \mathrm{m}^{2}$ $(\mathrm{SD}=85)$. The results obtained in $1967 / 68$ were similar to these. Moreover, the numbers of patients with a condition requiring medical treatment were roughly the same, 24 in the exposed group and 23 controls.

Distribution of risk factors among cases and controls To scrutinize the distribution of some coronary risk factors (or indicators) among cases and controls in 1972 we formed further groups, one comprising those exposed men who had experienced myocardial infarction during the follow-up period, the cases, and one comprising those exposed men free from disease, the controls. Similarly groups of infarction cases and controls were formed from the whole population under study (exposed + unexposed subjects). The distribution of the same risk factors was studied among typical angina pectoris cases and controls in analogous groups. The values of the risk factors were those obtained in 1967/68. Table 6 indicates the results among the myocardial infarction cases and controls of the two cohorts combined. Those with infarctions had higher systolic and diastolic blood pressures and cholesterol levels. Furthermore there were more cases born in Eastern Finland and the cases had smoked more than the controls. The cases also had slightly higher one-hour glucose mean values. The corresponding differences between those with typical angina and their controls were much smaller and had a higher probability of being due to chance. These results show, as expected, the importance of the risk factors measured in the prediction of future coronary attacks.

\section{Dose-response considerations}

Age introduces some confusion into the evaluation of a dose-response relationship. In this study the duration of exposure or the exposure index represents dose, and CHD represents the response expressed as either the prevalence of angina or as the five-year incidence of nonfatal and fatal coronary infarctions (i.e., the variables for which group differences were found). Such an evaluation is particularly difficult in this special instance by reason of the relatively low number of infarctions, a difficulty that can be overcome in a prospective design only by the observation of larger groups or by extending the observation period. In the present situation neither course of action was practicable. A comparative retrospective (case-control) design offered itself as a natural alternative, since the confounding effect of age can be countered by a matching procedure. In principle all of the different outcomes could be treated separately by means of this approach, but in this instance it seemed practical to combine fatal and nonfatal cases. In the first comparison, accordingly, the cases comprise all those who had incurred fatal or nonfatal coronary infarction between 1 July 1967 and 30 June 1972, and the controls were age-matched exposed workers free from CHD at the examination made in 1972. In a similar manner those with typical angina in 1972 were compared with age-matched controls without CHD from the exposed group. Table 7 indicates that those with infarction had a slightly longer exposure time and a slightly higher exposure index than did their controls. The difference may be attributable to chance, however, by virtue of the wide variation in exposure indicators. The situation was quite similar in regard to angina (Table 8). Consequently no definite dose-response relationship could be found by the use of this approach. 
TABLE 6

Mean Values (M) and Standard Deviations (SD) for Systolic and Diastolic Blood Pressure, Plasma Glucose 1 Hour after Glucose Load, Serum Cholesterol level, Birth Districts, and Cigarette Smoking among Infarction Cases and Controls in the Whole Population under Study aNd the Two-tailed Significance leVels (P Values)

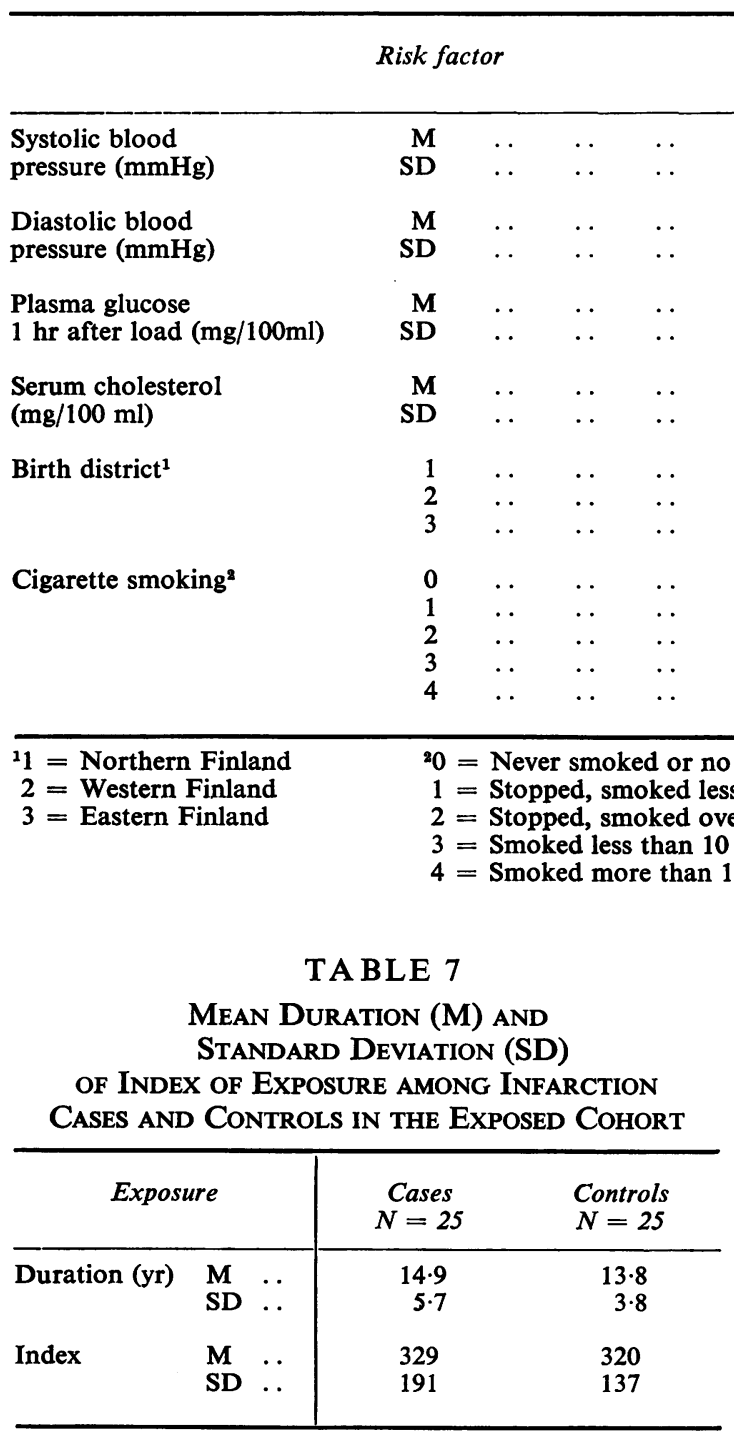

\section{Discussion}

In a previous report (Hernberg et al., 1973) an explanation was given for our belief that a causal relationship exists between exposure to carbon disulphide and increased mortality from CHD; this belief had the following basis:

(1) at least three different research groups have shown coronary mortality that was higher than expected among viscose rayon workers (Tiller et al., 1968; Mowé, 1971; Hernberg et al., 1973);

(2) the strength of association is great (a relative risk of five in our study);

(3) the literature contains data indicating several biochemical mechanisms that may explain this phenomenon (cf. Hernberg et al., 1973).

It is evident from the present study that not only 
is coronary mortality increased but also that milder forms of CHD are more common among viscose rayon workers, namely, clinical non-fatal infarctions and a history of angina. Nevertheless a clear trend becomes discernible: the highest relative risk was apparent in the severest outcome or fatal attacks, and the lowest for the mildest forms or history of angina and coronary ECGs (Table 5). In reality the latter displayed such slightly increased rates of prevalence that they may well be attributable to chance. A trend of this nature suggests that carbon disulphide may primarily induce a deterioration in the prognosis of CHD at a given severity of atherosclerotic changes in the coronary arteries. However, since angina was also commoner among the exposed group, it is possible that the total incidence and prevalence of CHD may also be elevated to some extent, with reservation for the inexact nature of the questionnaire technique. Careful necropsy studies of subjects exposed to carbon disulphide would be required for more exact information on this point. An attempt was made to check the necropsy reports in this series in retrospect but, as could be expected, this was unfruitful. Necropsies had been performed in no more than eight cases, and no conclusions could be drawn from such a small series. Apparently elucidation of the mechanism by which carbon disulphide damages the cardiovascular system needs well-planned prospective necropsy studies performed by experienced pathologists, most feasibly in the form of cross-national collaboration with one or more reference laboratories, as was proposed by Schilling (1970).

During the five-year follow-up the exposed group, initially 343 men in 1967, showed an excess CHD mortality of 11 cases. Additionally, seven excess cases of first clinical non-fatal infarction were recorded, and at the end of the follow-up there was an excess prevalence of 35 cases of angina (22 if only typical angina is counted). These figures clearly indicate the severity of the problem and urge vigorous preventive action. The first question that arises is whether or not the threshold limit value (TLV) of $20 \mathrm{ppm}$ recommended hitherto by the American Conference of Governmental Industrial Hygienists (1973) is safe. As is observable from Figs. 1 to 4 , the concentrations measured during approximately the last ten years have been around or below $20 \mathrm{ppm}$, with the exception of spinning departments, in which they have been between 20 and $30 \mathrm{ppm}$. In the evaluation of these data it must be borne in mind that the sampling was done only once monthly.

As a rule sampling was restricted to so-called normal working conditions. Everyone familiar with the work in a viscose rayon plant knows that spinners in particular, but also other workers, may have repeatedly to work with the machine coverings open or even inside them during a working shift if anything goes wrong, a rather frequent occurrence. Similar circumstances arise during repair and maintenance of the machines. Furthermore, during the installation of new machines and under some other conditions the ventilation system may be inadequate. Since the sampling scheme was directed towards monitoring average concentrations under normal working conditions, it is more than probable that these peak exposures were not included. On the other hand, during periods with no disturbances workers may spend several hours of their working shift in ventilation surveillance rooms with practically no exposure at all. No account is here taken of these periods. Even more importance is attached to the fact that in 1967/68 132 of the 343 men examined were no longer working in exposed conditions; in 1972 the proportion was 140 of 316 which implies that about $40 \%$ of them had not undergone any further exposure at all during the follow-up period. The conclusion is that the deleterious effects of carbon disulphide appear irreversibly to accelerate the development of CHD, which further aggravates the problem. When endeavours are made to clarify the situation to enable at least something to be said about the exposure-effect relationship, the following points seem important: (1) The concentrations measured were mostly of the order of less than 10 to $30 \mathrm{ppm}$; (2) the frequency of exposure peaks and their intensity were unknown; (3) workers had usually spent less than eight hours per shift under conditions of exposure to carbon disulphide; and (4) nearly half of them had had no exposure at all during the follow-up. When all this is taken into consideration, it must be admitted that estimation of the personal exposure of workers was impossible. Steps are now taken by the factories to measure the personal exposure to $\mathrm{CS}_{2}$.

When excess mortality and morbidity from CHD occur under the true conditions represented by measured concentrations within the range observed, the conclusion to be drawn is that they are not safe at all. Whether or not those measurements reflect personal exposure is irrelevant from the standpoint of evaluating the safety of the TLV, since this value is the limit for the overall work room air, and not for personal exposure. Therefore levels of 10 to $30 \mathrm{ppm}$ with occasional periods of high concentrations must be regarded as unsafe. It seems reasonable, considering the seriousness of the outcome (i.e., death), to be more than normally cautious and to require an adequately broad safety margin. As stated by the ACGIH (1971), the limit of $20 \mathrm{ppm}$ appears to have a narrow margin of safety. On the basis of this reasoning this limit seems to be too high and accordingly the Finnish authorities did not hesitate to lower the Finnish TLV to $10 \mathrm{ppm}$ in 1972. Another preventive measure, probably at 
least as important, is the avoidance of exposure peaks. On a short-term basis this is best achieved by the rigorous use of personal protective equipment, which by reason of its inconvenience, such as during work inside the coverings, requires special arrangements. However, technical solutions are clearly to be preferred in the long run.

In conclusion, it may be stated that the causeeffect relationship between carbon disulphide and CHD is well established. More knowledge of the exposure-response relationship is now urgently needed so that the non-effect level can be defined. With regard to this, it is crucial to produce reliable and representative exposure data, and here the monitoring of personal exposure should be given close attention. Indeed, future research workers should concentrate on the validity of their exposure data rather than on overloading their investigations with unnecessary clinical measurements. Primarily this requires agreement on monitoring methods and strict adherence to them. A great deal remains to be done in this area.

We wish to thank Kalervo Mäkinen, M.D., plant physician of the 'Yhtyneet Paperitehtaat' paper-mill, for valuable help with the comparison group, and E. Sorsa, M.sc., for providing the exposure data. Mrs. Pirjo Fahlström helped with the statistical calculations, and Miss Ritva Halonen and Mrs. Outi Marila coded the ECGs. Our thanks are also due to the managements, industrial nurses, and workers of both plants for their understanding attitude and their help with the practical arrangements. The forceful preventive measures started immediately by the management of the Säteri viscose rayon plant when the results became known, and the company's open policy deserves special acknowledgment. This study has been aided in part by research grants from the Sigrid Jusélius Foundation.

\section{References}

American Conference of Governmental Industrial Hygienists (1971). Documentation of the Threshold Limit Values for Substances in Workroom Air. 3rd edition. Cincinnati, Ohio, USA.

(1973). Threshold Limit Values for Chemical Substances and Physical Agents in the Workroom Environment with Intended Changes. Cincinnati, Ohio, USA.
Blackburn, H., Keys, A.. Simonson, E., Rautaharju, P., and Punsar, S. (1960). The electrocardiogram in population studies. A classification system. Circulation, 21, 1160-1175.

Cirla, A., Villa, A., and Tomasini, M. (1972). Indagine sull'incidenza di coronaropatie nei lavoratori di una industria di viscosa-rayon, esposti a solfuro di carbonio. Medicina del Lavoro, 63, 431-441.

Goto, S. and Hotta, R. (1967). The medical and hygienic prevention of carbon disulphide poisoning in Japan. In Toxicology of Carbon Disulphide, edited by $\mathrm{H}$. Brieger and J. Teisinger, pp. 219-230. Excerpta Medica Foundation, Amsterdam.

Hernberg, S., Nordman, C-H., Christiansen, V., and Virkola, P. (1971). Blood lipids, glucose tolerance, and plasma creatinine in workers exposed to carbon disulphide. Work-Environment-Health, 8, 11-16.

_- Nurminen, M., and Tolonen, M. (1973). Excess mortality from coronary heart disease in viscose rayon workers exposed to carbon disulphide. WorkEnvironment-Health, 10, 93-99.

- Partanen, T., Nordman, C-H., and Sumari, P. (1970). Coronary heart disease among workers exposed to carbon disulphide. British Journal of Industrial Medicine, 28, 313-325.

Mowé, G. (1971). Coronary heart disease and occupational exposure to carbon disulfide. Abstract of the Second International Symposium on Toxicology of Carbon Disulfide, edited by Dusan Djurić et al. Institute of Occupational and Radiological Health, Beograd.

Rose, G. A. (1968). Variability of angina. Some implications for epidemiology. British Journal of Preventive and Social Medicine, 22, 12-15.

Schilling, R. S. F. (1970). Oral statement. Meeting on $\mathrm{CS}_{2}$, arranged by the TUC Centenary Institute of Occupational Health, London.

Tiller, J. R., Schilling, R. S. F., and Morris, J. N. (1968). Occupational toxic factor in mortality from coronary heart disease. British Medical Journal, 4, 407-411.

Zeiner-Henriksen, T. (1972). Repeatability at interview of symptoms of angina and possible infarction. Journal of Chronic Diseases, 25, 407.

World Health Organization (1963). Réunion technique sur les enquêtes épidemiologiques concernant la fréquance des cardiopathies ischémiques. Bureau Régional de l'Europe, Copenhagen.

Received for publication 26 April 1974

Accepted for publication 27 June 1974 